\title{
Invited comment to: European Hernia Society guidelines on prevention and treatment of parastomal hernias
}

\author{
J. M. V. Faylona ${ }^{1}$
}

Received: 18 December 2017 / Accepted: 18 December 2017 / Published online: 4 January 2018

○) Springer-Verlag France SAS, part of Springer Nature 2018

Parastomal hernia is the most frequent problem encountered after an enterostomy procedure. Even with advances in colorectal surgery, the creation of a stoma will probably not disappear in the near future. There are varying incidences of parastomal hernia formation depending on the type of colostomy or enterostomy done with the end colostomy having the highest in terms of parastomal hernia formation. Even the type of repair for this type of hernia is plagued with challenges due to its high recurrence rate.

We at the Asia Pacific Hernia Society would like to congratulate the European Hernia Society for coming up with these guidelines on the prevention and management of parastomal hernias. Though the study revealed a lot of questions that need to be answered, this opens up a lot of avenue for our institutions to do more research in response to the unanswered questions by these guidelines. One particular interesting recommendation of this guideline is the use of prophylactic mesh in the prevention of parastomal hernias. This particular recommendation entails more studies in the future to address its effectiveness for this problem.
These guidelines will be of great use to general surgeons, and we at the Asia Pacific Hernia Society appreciate the opportunity to review these guidelines and would like to endorse this to our members as a guide in the management of this problem. We hope that this collaboration opens more future collaboration between the EHS and us.

\section{Compliance with ethical standards}

Conflict of interest I have no conflict of interest related to this invited commentary.

Ethical approval This study design is confirmed to ethical standards.

Human and animal rights This article does not contain any studies with human participants or animals performed by the author.

Informed consent For this type of study, informed consent is not required.
This comment refers to the article available at https://doi. org/10.1007/s 10029-017-1697-5.

\section{J. M. V. Faylona}

mackymd@yahoo.com

1 University of the Philippines Manila, Manila, Philippines 